\title{
Survival, Proliferation and Cell Cycle of Swine Fibroblast after Infection with Salmonella enterica
}

\author{
Mizuki Masuda', Yijie Guo',2, Kengo Kuroda', Jun Xu' ${ }^{1}$, Hiroshi Yoneyama1, Tomokazu Fukuda ${ }^{3}$, \\ Bernard Mudenda Hang'ombe ${ }^{4}$, Katsuya Okuno ${ }^{1}$, Junko Nishimura ${ }^{*}$, Emiko Isogai ${ }^{*}$ \\ ${ }^{1}$ Laboratory of Animal Microbiology, Graduate School of Agricultural Science, Tohoku University, Sendai, Japan \\ ${ }^{2}$ Department of Immunobiology and Pathogenic Biology, Medical School of Xi'an Jiaotong University, Xi'an, China \\ ${ }^{3}$ Laboratory of Cell Engineering and Molecular Genetics, Faculty of Science and Engineering, Iwate University, Morioka, Japan \\ ${ }^{4}$ Department of Clinical Microbiology, School of Veterinary Medicine, University of Zambia, Lusaka, Zambia \\ ${ }^{5}$ Laboratory of Nutrition and Life Sciences, Department of Biotechnology and Environmental Engineering, Faculty of Engineering, \\ Hachinohe Institute of Technology, Hachinohe, Japan \\ Email: *emiko@bios.tohoku.ac.jp, *jnishimura@hi-tech.ac.jp
}

How to cite this paper: Masuda, M., Guo, Y.J., Kuroda, K., Xu, J., Yoneyama, H., Fukuda, T., Hang'ombe, B.M., Okuno, K., Nishimura, J. and Isogai, E. (2016) Survival, Proliferation and Cell Cycle of Swine Fibroblast after Infection with Salmonella enterica. Advances in Microbiology, 6, 942-952. http://dx.doi.org/10.4236/aim.2016.613088

Received: August 11, 2016

Accepted: November 6, 2016

Published: November 9, 2016

Copyright $\odot 2016$ by authors and Scientific Research Publishing Inc. This work is licensed under the Creative Commons Attribution International License (CC BY 4.0).

http://creativecommons.org/licenses/by/4.0/

\section{(c) (i) Open Access}

\begin{abstract}
Food-borne salmonellosis continues to be a major health concern worldwide. Carrycontamination of Salmonella frequently occurs in meat production. We focused on cell dynamics of swine fibroblasts after infection with Salmonella enterica serovar Enteritidis and Typhimurium, because fibroblast can be a target cell for Salmonella latent infection. It was found that both $S$. Enteritidis and $S$. Typhimurium were able to adhere and invade to swine fibroblasts. The proliferations in fibroblasts were different between each serovar. $S$. Enteritidis reached to the maximum at $24 \mathrm{hr}$ after infection while $S$. Typhimurium did not. In addition, the decrease in the $\mathrm{G}_{0} / \mathrm{G}_{1}$ phase cells and increase in $\mathrm{G}_{2} / \mathrm{M}$ phase cells on the fibroblast were observed by both Salmonella infection. Cell death including apoptosis in the cells was inhibited by the infection of Salmonella. These results suggest that nontyphoidal Salmonella can survive for the long term by modifying bacterial cell proliferation and preventing cell death of host cells.
\end{abstract}

\section{Keywords}

Salmonella enterica, Fibroblast, Swine, Cell Death, Cell Cycle

\section{Introduction}

Salmonella enterica causes various diseases, particularly, nontyphoidal salmonellae are very important in reportable food-borne infections. Salmonella is an intracellular pathogen that can invade eukaryotic cells and manage to survive in the living host cell [1] 
[2] [3]. It is well known that this bacteria is able to invade via Type Three Secretion System (TTSS) encoded in Salmonella Pathogenicity Island 1 (SPI-1) [4]. When Salmonella invades to host cells, the SPI-1 effector protein of the TTSS is injected into epithelial cells, thereby causing rearrangement of actin cytoskeleton [5] [6] [7], membrane ruffling and formation of micropinosomes [8]. As a case of cytoskeletal rearrangement, it is revealed that SPI-1 proteins SipABCD, SopE and SopE2 are involved [9].

In the present, it has been found that the infection route of Salmonella Typhimurium against fibroblast cells was quite different from that of epithelial cells, in which the SPI-1 effectors SipB and SipC were unnecessary. And this strain is able to suppress cell growth by stopping cell division in fibroblast cells after invasion [10] [11] [12]. Based on these findings, it is considered that $S$. Typhimurium could alter the routes into fibroblasts, and persistent infection and asymptomatic carrier are caused.

Although it has been known the importance of salmonellosis to public health, the mechanism of the Salmonella carrier state hasn't been well known still now. We examined the invasion of Salmonella into fibroblasts, because there was a risk of giving rise to the persistent infection. In addition, we show here invasion and proliferation of $S$. Typhimurium in the fibroblasts differs from that of $S$. Enteritidis.

\section{Materials and Methods}

\subsection{Bacterial Strains and Swine Fibroblast Cell Line}

Salmonella enterica serovar Enteritidis strain zSE1 isolated in Zambia and Typhimurium wild type strain st1wt were cultured properly in Trypticase Soy Broth (TSB) at $37^{\circ} \mathrm{C}$ for $18 \mathrm{hr}$ [13]. Pig embryonic fibroblasts (PEFs), which infected with simian vacuolating virus 40 large $\mathrm{T}$ fragment (PEFs-SV40) to achieve immortalization, used in this study [14]. Cells were cultured in Dulbecco's modified Eagle's medium (DMEM) (Nacalai Tesque Inc., Kyoto, Japan) with 10\% PBS and 1\% antibiotic-antimycotic mixed stock solution (Nacalai Tesque Inc.) at $37^{\circ} \mathrm{C}$ in $5 \% \mathrm{CO}_{2}$. Cells were maintained under exponential growth condition and used as the host cells in further experiments.

\subsection{Bacterial Infection Assays}

PEFs were seeded in a 24-well-plate to reach a density of $1.0 \times 10^{5}$ cells/well at the time of infection. The medium was changed to DMEM with $10 \%$ FBS (without antibiotics) 2 $\mathrm{hr}$ before bacterial infection to eliminate any potential effects of the antibiotics. PEFs were infected with overnight cultured bacteria at a multiplicity of infection (MOI) of 5:1 (bacteria to eukaryotic cells). To count the adhesive bacteria at $0,20,60$, and 100 min after the infection, wells were washed with PBS containing $0.1 \%$ (wt/vol) sodium dodecyl sulfate (SDS) (Wako Pure Chemical Industries Ltd., Osaka, Japan) and 1\% (vol/vol) Triton X-100 (Wako Pure Chemical Industries Ltd.) as lysis buffer. The invasive bacteria were counted, and cells were washed with PBS repeatedly. Fresh culture medium containing $100 \mu \mathrm{g} / \mathrm{ml}$ gentamicin was added for $2 \mathrm{hr}$ post-infection, and then the cultured cells were lysed with lysis buffer. 


\subsection{Immunofluorescence Microscopy}

Extracellular (adherent) and intracellular bacteria were stained by immunofluorescent microscopy by the methods of Aiastui et al. [10]. Briefly, extracellular bacteria were stained in nonpermeabilized cells with polyclonal rabbit anti-Salmonella lipopolysaccharide (LPS) antibodies ( $S$. Enteritidis $\mathrm{O} 4$ and $S$. Typhimurium O9, Denka Seiken Co., Ltd, Tokyo, Japan), followed by anti-rabbit Alexa Fluor $594 \mathrm{~F}(\mathrm{ab}$ ')2 fragment antibody (Invitrogen, CA, USA). Upon permiabilization by treatment with $0.2 \%$ Triton X-100, intracellular bacteria were stained with anti-Salmonella LPS antibody above, followed by anti-rabbit Alxa-Fluor $488 \mathrm{~F}\left(\mathrm{ab}^{\prime}\right) 2$ fragment antibody (Invitrogen) as secondary antibodies.Cells were observed with a Fluorescent microscope (FSX 100, Olympus, Tokyo, Japan).

\subsection{Intracellular Proliferation}

Fresh DMEM medium containing $100 \mu \mathrm{g} / \mathrm{ml}$ gentamicin was added into $2 \mathrm{hr}$ infected fibroblast. After cultivation for $24 \mathrm{hr}$, PEFs were dissolved in lysis buffer and intracellular bacterial numbers were counted.

\subsection{Live Cell Count}

Bacteria-infected PEFs (MOI $=5: 1$ as described above) were treated at $0,20,60,100$ min after the infection with $0.05 \%$ Triton X-100 and cells were collected. Cells were mixed with trypan blue (Invitrogen) and living cells were counted using a CSTI Counter (Cell Science \& Technology Institute, Inc., Miyagi, Japan). In order to assess the effects of intracellular pathogens and long-term infection, the medium was changed to fresh medium containing $100 \mu \mathrm{g} / \mathrm{ml}$ gentamicin $2 \mathrm{hr}$ after infection. After gentamicin treatment for $24 \mathrm{hr}$, live PEFs were counted according to mentioned.

\subsection{MTT Assay}

PEFs were seeded in a 96-well-plate and incubated for $24 \mathrm{hr}$ to reach a density of $3.0 \times$ $10^{3}$ cells/well at the time of infection. The medium was changed to DMEM with $10 \%$ FBS (without antibiotics) $2 \mathrm{hr}$ before bacterial infection to eliminate any antibiotic effects. Cells were infected with Salmonella (MOI $=5: 1)$, and then $10 \mu \mathrm{l}$ of MTT reagent from the MTT Cell Proliferation Assay kit (Funakoshi Co., Ltd., Tokyo, Japan) was added immediately after infection. After post-infection for $2 \mathrm{hr}$, the medium was changed to DMEM containing $100 \mu \mathrm{g} / \mathrm{ml}$ gentamicin, and MTT reagent was added to each samples at 0,2 , and $24 \mathrm{hr}$.

\subsection{Apoptosis and Cell Cycle Assay}

Apoptosis of infected cell was analyzed with Muse ${ }^{\mathrm{TM}}$ Cell Analyzer (Merck Millipore Inc., Darmstadt, Germany).PEFs were inoculated $0.1 \times 10^{5}$ cells per well. $S$. Enteritidis or $S$. Typhimurium was added into well in the ratio of 5:1 (MOI) and incubated for 2 hr. After infection, PEFs were washed with PBS and collected with $0.05 \%$ trypsin. And then PEFs were centrifuged $(800 \times \mathrm{g})$ and washed with PBS. Infected PEFs were col- 
lected with $0.05 \%$ trypsin and added Muse Annexin \& Dead Cell Reagent and standing for $30 \mathrm{~min}$ at room temperature in a dark place. Apoptotic cells were detected with the analyzer. Furthermore, apoptosis profile of PEFs infected with $S$. Enteritidis zSE1 after infection for $24 \mathrm{hr}$ was monitored using the flow cytometry.

The cell cycle of PEFs was also analyzed by using the Muse ${ }^{\mathrm{TM}}$ Cell Cycle Assay Kit (Merck Millipore Inc.), according to the procedure described by the manufacturer. Infected PEFs were collected with $0.05 \%$ trypsin, centrifuged $(800 \times \mathrm{g})$, and washed with PBS. Collected cells were suspended in cold $70 \%$ ethanol and incubated for over $3 \mathrm{hr}$ at $-20^{\circ} \mathrm{C}$ for fixation. Fixed cells were washed with PBS and stained with the cell cycle reagent for $30 \mathrm{~min}$. Samples were measured by using the above analyzer.

\subsection{Statistical Test}

In this study, all of the experiments were carried out with at least triplicated samples. Mean and standard deviations were calculated from the multiple data. The statistical significance was evaluated unpaired $t$-test. After statistical analysis, $p$ values of less than 0.05 were considered statistically significant.

\section{Results and Discussion}

\subsection{Infection to Swine Fibroblasts}

Although it has been revealed that fibroblasts are highly involved in the persistence of pathogenic Salmonella [15], the mechanisms of long-term and persistent infection of Salmonella enterica are still unknown. In this study, we investigated Salmonella-fibroblast interactions to clarify the survival strategy of Salmonella in the host fibroblasts.

We first confirmed the infection of Salmonella to PEFs by conducting infection assay and immunofluorescence. Each cell of $S$. Enteritidis and Typhimurium adhered approximately $1 \%$ for a start, and adherent cell number was increased time-dependently (Figure 1(a)). At $100 \mathrm{~min}$, adherent number of $S$. Typhimurium was significantly higher than that of $S$. Enteritidis $(\mathrm{P}<0.01)$. Cell invasion was observed after $60 \mathrm{~min}$ of the infection. $S$. Typhimurium invaded cells more aggressively than $S$. Enteritidis (Figure 1(b), P $<0.01$ at $60 \mathrm{~min}$ after the infection). The states infected with $S$. Enteriditis or $S$. Typhimurium were photographed with a fluorescent microscope and typical photo-images at $24 \mathrm{hr}$ after $S$. Typhimurium infection were showed (Figure 2). Furthermore, the intracellular proliferation of Salmonella cells was different between $S$. Enteritidis and $S$. Typhimurium, i.e., $S$. Enteritidis reproduced sharply after invasion to PEFs, on the other hand, $S$. Typhimurium was almost not (Figure 3, $\mathrm{P}<0.01$ ). Namely, $S$. Enteritidis zSE1 reached $1.28 \times 10^{4} \mathrm{cfu}$ after infection for $24 \mathrm{hr}$, while $S$. Typhimurium st1wt couldn't proliferate in host cells and only reached $3.3 \times 10^{2} \mathrm{cfu}$.

\subsection{Influences to Viability and Lifespan of Host Fibroblast}

In order to assess the influence of host cells infected with pathogenic Salmonella, we analyzed the viability and proliferation of infected PEFs. The number of living infected 
Adhesion

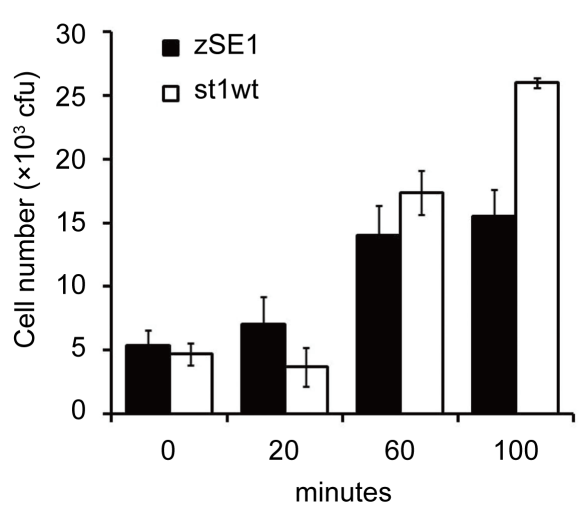

(a)

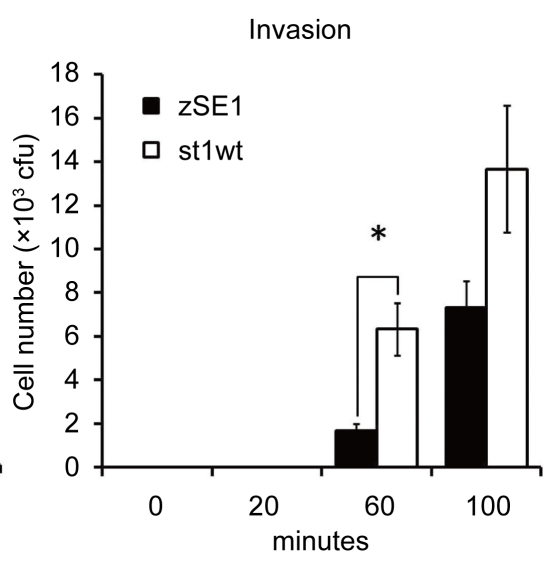

(b)

Figure 1. Chronological changes of adhesion and invasion on Salmonella enterica. (a) Cell numbers of $S$. Enteritidis or Typhimurium which can adhere to PEFs. (b) Cell numbers of $S$. Enteritidis or Typhimurium which can invade to PEFs. ${ }^{*}$ : $<0.01$ unpaired $t$-test.
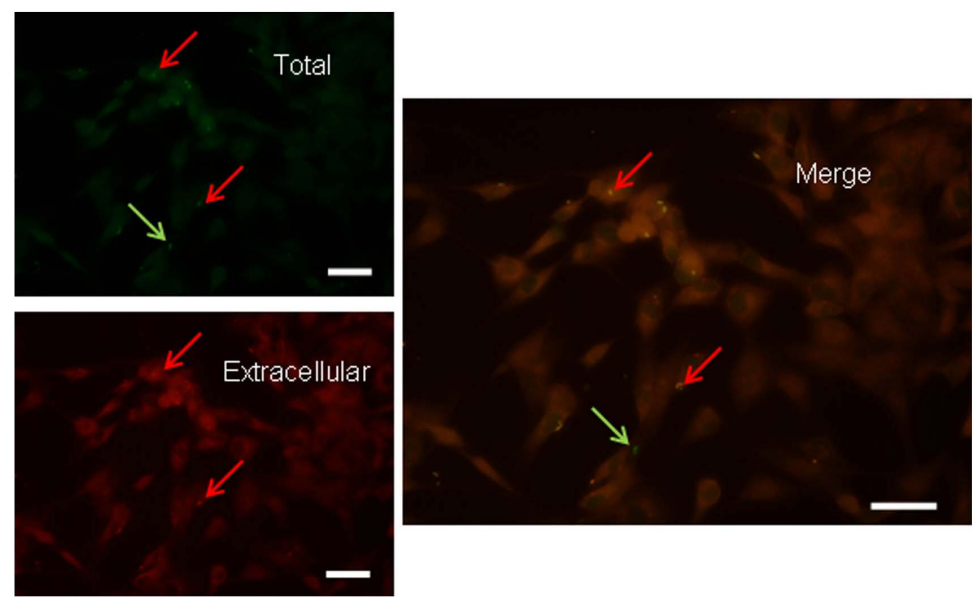

Figure 2. Fluorescent microscopy photographs of $S$. Typhimurium after infection for $24 \mathrm{hr}$. Bar: $50 \mu \mathrm{m}$. Red arrow: adhesion, green arrow: invasion.

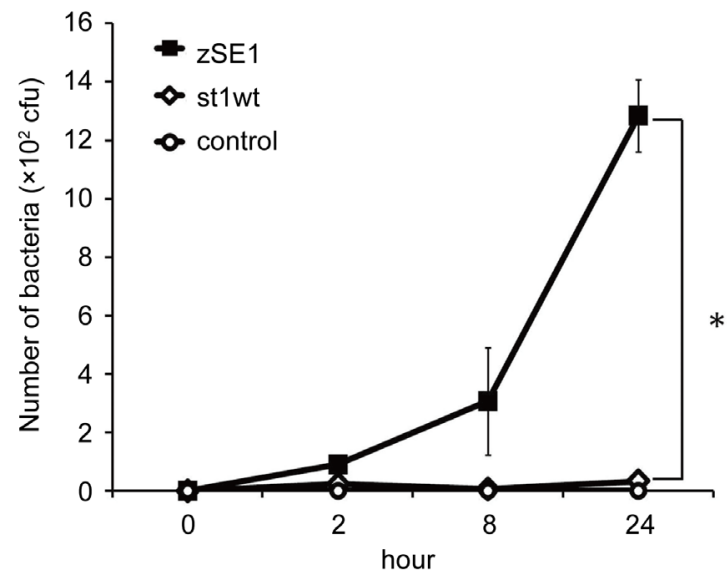

Figure 3. Chronological changes of bacterial numbers on intracellular Salmonella enterica. ${ }^{\star}$ : $<$ 0.01 , unpaired $t$-test. 
PEFs was counted after trypan blue staining. As a result, it was found that living cells were increased after infection with both Salmonella strains compared to non-infected cells (Figure 4). The proliferation of living PEFs was measured by MTT assay after 0, 2 and $24 \mathrm{hr}$ infection (Figure 5). The proliferation of PEFs infected for $24 \mathrm{hr}$ was remarkably increased, particularly, a significant difference was revealed on $S$. Typhimurium. These results indicate that Salmonella is able to survive within host fibroblasts and enhance the proliferation of host cells. It is found that $S$. Typhimurium led to enhance the proliferation in epithelial cells [16] and suppress it in dendritic cells and fibroblasts [11] [17]. Furthermore, $S$. Enteritidis into human fibroblasts increased during 1 day after infection and could survive until 14 to 28 days [18]. Based on these findings, it is considered that Salmonella grows rapidly in fibroblast and gradually controls

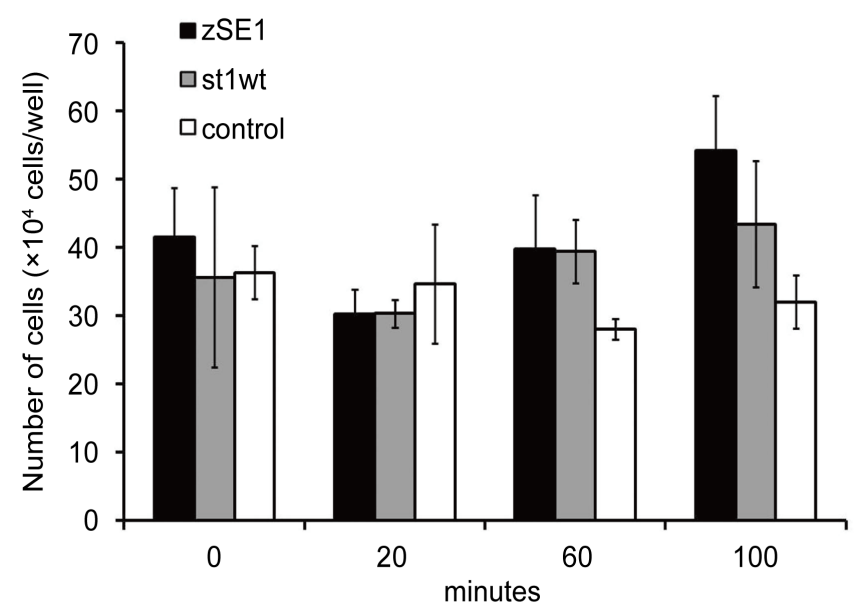

(a)

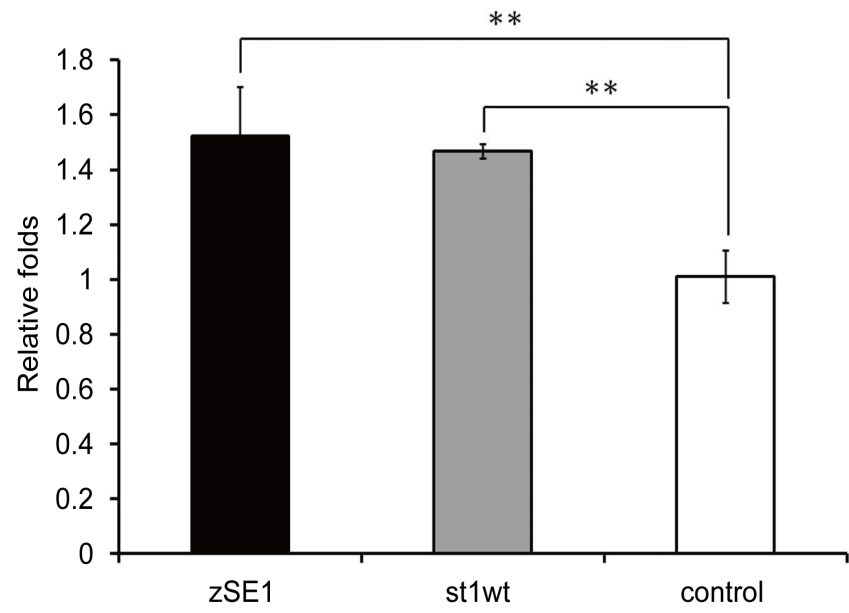

(b)

Figure 4. Proliferation of PEFs infected with zSE1 or st1wt. (a) The number of PEFs infected with $S$. Enteritidis or Typhimurium and non-infected-PEFs were counted using the trypan blue method. 0, 20, 60, 100 min after infection, cell number of PEFs infected with bacteria tended to be larger that of non-infected PEFs. (b) $24 \mathrm{hr}$ after infection, PEFs infected with zSE1 or st1wt were about 1.52 fold or 1.47 fold respectively compared with non-infected PEFs. ${ }^{* *}$ : $\mathrm{P}<0.05$, unpaired $t$-test. 


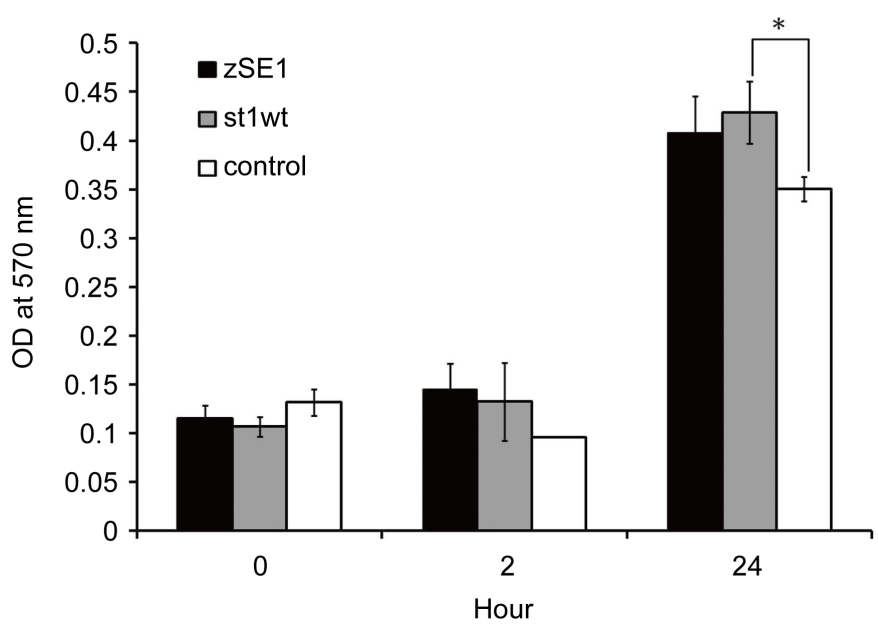

Figure 5. Time-lapse changes of cell proliferation on host PEFs. Cell viability was measured by MTT cell proliferation assay. Colorimetrical formazan produced from live cell metabolism were detected as absorbance at $570 \mathrm{~nm}$. *: $\mathrm{P}<0.01$ unpaired $t$-test.

them after that, and Salmonella is possible long-term survival by repressing the proliferation in restricted host cells.

\subsection{Effect to Viability of Fibroblast}

We demonstrated the cell death pattern of host cells after Salmonella infection as shown in Figure 6. As shown in Figure 7, apoptotic cells counted was 1\% - 1.5\% (significantly higher than control) at the beginning of the infection. After $24 \mathrm{hr}$ infection, the percentage of apoptotic cells significantly increased in non-infected cells; in contrast, the percentage of apoptotic cells was approximately $0.5 \%$ on Salmonella infected cells. Total dead cell number was also decreased by the Salmonella infection (data not shown).

To further explain such phenomenon, cell cycle of infected cells was analyzed by using a Cell Analyzer. The cell cycle of infected or non-infected PEFs was measured by flow cytometry $24 \mathrm{hr}$ after addition of bacteria. The results revealed that $\mathrm{G}_{0} / \mathrm{G}_{1}$ phases of infected cells were reduced and the $\mathrm{G}_{2} / \mathrm{M}$ phases were prolonged compared with non-infected cells, respectively (Figure 8). It has been found that enteropathogenic Escherichia coli and enterohaemorrhagic E. coli infused effector protein Cif to eukaryotic host cells and led to arrest cell cycle, and the barrier of the epithelium cell became weak by stopping a cell cycle, and bacteria became easy to infect cells [19]. And the $\mathrm{G}_{0}$ phase was longer to repair DNA in cell cycle [20], the apoptosis was caused when DNA damage could not repair [21] [22]. In addition, it has been known that Salmonella led to induce apoptosis of host chicken fibroblasts [23], and the ratio of apoptotic PEFs infected with Salmonella Enteritidis or Typhimurium might be increased. Based on these findings, it seems that Salmonella infection induces the alteration of the cell cycle on host PEFs, and interrupts apoptosis of the host cell to survive in host cells. Namely, Salmonella of the intracellular parasitism may lead to repress cell cycle after invasion. 


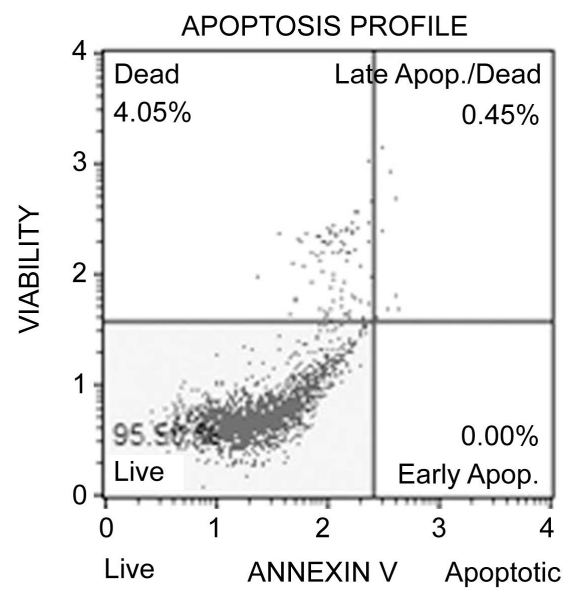

(a)

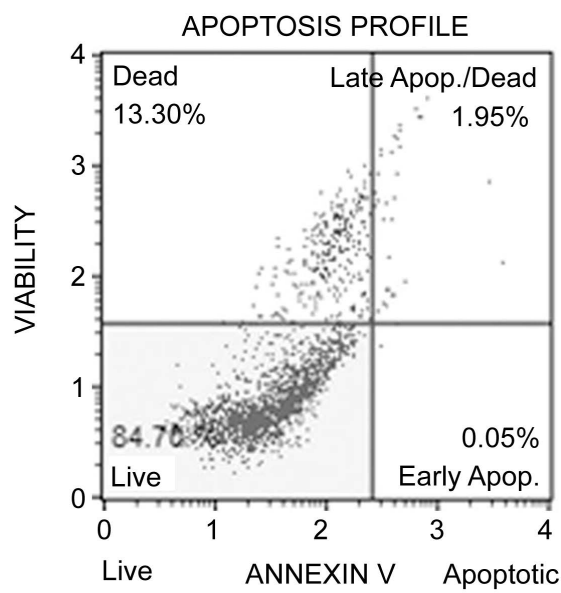

(b)

Figure 6. Dead /live cells and apoptosis profile of PEFs infected with $S$. Enteritidis zSE1. (a) Infected cells. (b) Control: non-infected cells.

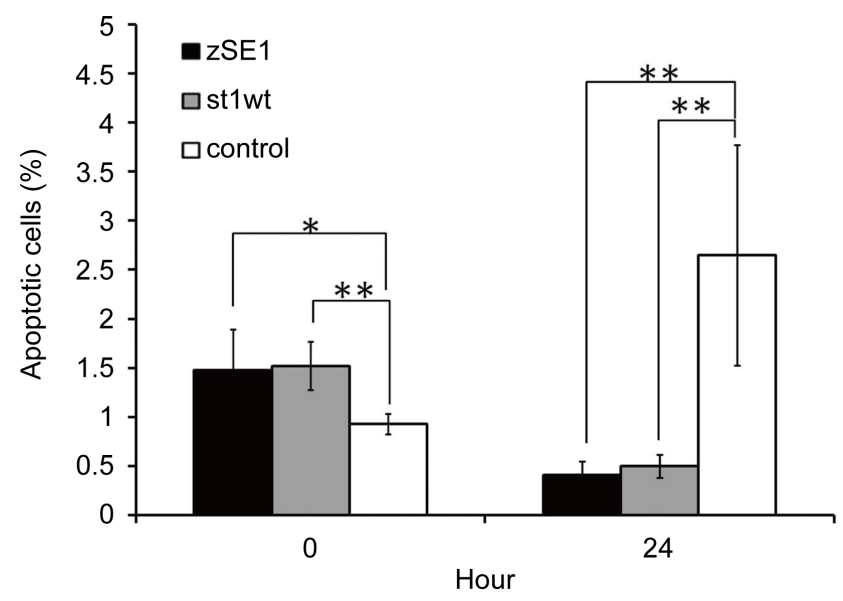

Figure 7. Proportion of apoptotic PEFs after infection with Salmonella enterica. Apoptosis caused by Salmonella enterica infection were detected by Annexin $\mathrm{V}$ using flow cytometry. ${ }^{\star}: \mathrm{P}<0.01$ and ${ }^{\star *} \mathrm{P}<0.05$, unpaired $t$-test. 

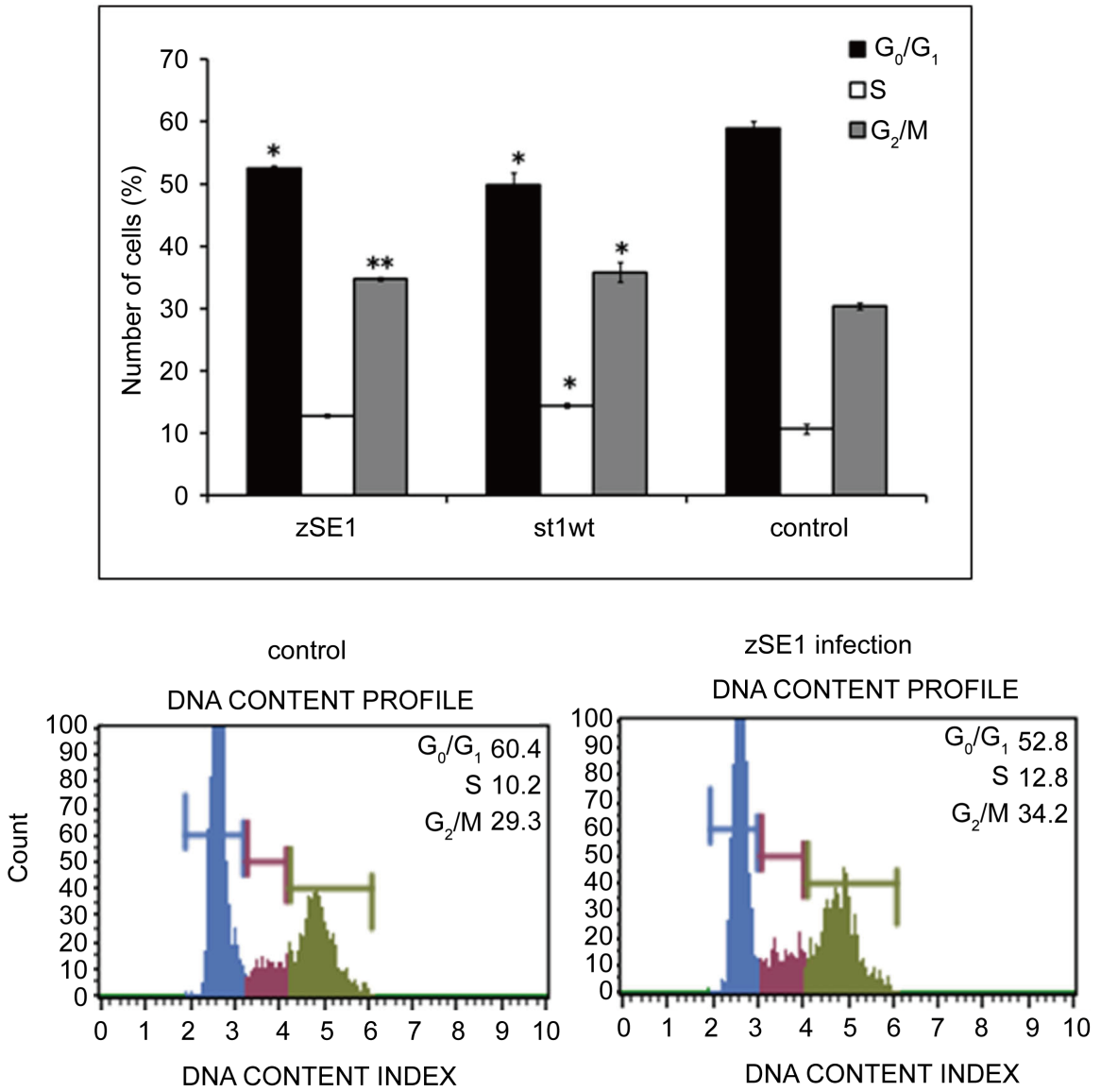

Figure 8. The ratio of cell cycle phase in PEFs after infection with Salmonella enterica. *: $\mathrm{P}$ $<0.01$ and ${ }^{* *}: \mathrm{P}<0.05$, unpaired $t$-test.

It has been known that bacteria are able to suit host cell environment by promoting the most successful conditions for infection [24]. In this study, we demonstrated that Salmonella was able to survive in fibroblasts by manipulating both lifespan and apoptosis of host cell. This phenomenon is intended to optimize the circumstances of Salmonella survival and promote the persistent infection of Salmonella in livestock. This series of strategy could be a notable fact that highlights new concepts of Salmonella infection of fibroblasts in domestic animals, and encourages people to reconsider the hidden issue in food safety.

\section{References}

[1] Hohmann, E.L. (2001) Nontyphoidal Salmonellosis. Clinical Infectious Diseases, 32, 263 269. http://dx.doi.org/10.1086/318457

[2] Wood, R.L. and Rose, R. (1992) Populations of Salmonella Typhimurium in Internal Organs of Experimentally Infected Carrier Swine. American Journal of Veterinary Research, 53, 653-658.

[3] Fedorka-Cray, P.J., Whipp, S.C., Isaacson, R.E., Nord, N. and Lager, K. (1994) Transmission of Salmonella Typhimurium to Swine. Veterinary Microbiology, 41, 333-344. http://dx.doi.org/10.1016/0378-1135(94)90029-9 
[4] Galán, J.E. and Wolf-Watz, H. (2006) Protein Delivery into Eukaryotic Cells by Type III Secretion Machines. Nature, 444, 567-573. http://dx.doi.org/10.1038/nature05272

[5] Finlay, B.B., Ruschkowski, S. and Dedhar, S. (1991) Cytoskeletal Rearrangements Accompanying Salmonella Entry into Epithelial Cells. Journal of Cell Science, 99, 283-296.

[6] Patel, J.C. and Galán, J.E. (2005) Manipulation of the Host Actin Cytoskeleton by Salmonella-All in the Name of Entry. Current Opinion in Microbiology, 8, 10-15. http://dx.doi.org/10.1016/j.mib.2004.09.001

[7] Zhou, D. and Galán, J. (2001) Salmonella Entry into Host Cells: The Work in Concert of Type III Secreted Effector Proteins. Microbes and Infection, 3, 1293-1298. http://dx.doi.org/10.1016/j.mib.2004.09.001

[8] Garcia-del Portillo, F. and Finlay, B.B. (1994) Salmonella Invasion of Nonphagocytic Cells Induces Formation of Macropinosomes in the Host Cell. Infection and Immunity, 62, 4641-4645.

[9] Hansen-Wester, I. and Hensel, M. (2001) Salmonella Pathogenicity Islands Encoding Type III Secretion Systems. Microbes and Infection, 3, 549-559. http://dx.doi.org/10.1016/S1286-4579(01)01411-3

[10] Aiastui, A., Pucciarelli, M.G. and García-del Portillo, F. (2010) Salmonella enterica serovar Typhimurium Invades Fibroblasts by Multiple Routes Differing from the Entry into Epithelial Cells. Infection and Immunity, 78, 2700-2713. http://dx.doi.org/10.1128/IAI.01389-09

[11] García-del Portillo, F. (2001) Salmonella Intracellular Proliferation: Where, When and How? Microbes and Infection, 3, 1305-1311. http://dx.doi.org/10.1016/S1286-4579(01)01491-5

[12] Knodler, L.A., Finlay, B.B. and Steele-Mortimer, O. (2005) The Salmonella Effector Protein SopB Protects Epithelial Cells from Apoptosis by Sustained Activation of Akt. The Journal of Biological Chemistry, 280, 9058-9064. http://dx.doi.org/10.1074/jbc.M412588200

[13] Isogai, E., Makungu, C., Yabe, J., Sinkala, P., Nambota, A., Isogai, H., Fukushi, H., Silungwe, M., Mubita, C., Syakalima, M., Hang'ombe, B.M., Kozaki, S. and Yasuda, J. (2005) Detection of Salmonella invA by Isothermal and Chimeric Primer-Initiated Amplification of Nucleic Acids (ICAN) in Zambia. Comparative Immunology, Microbiology, and Infectious Diseases, 28, 363-370. http://dx.doi.org/10.1016/j.cimid.2005.10.001

[14] Donai, K., Kiyono, T., Eitsuka, T., Guo, Y., Kuroda, K., Sone, H., Isogai, E. and Fukuda, T. (2014) Bovine and Porcine Fibroblasts Can Be Immortalized with Intact Karyotype by the Expression of Mutant Cyclin Dependent Kinase 4, Cyclin D, and Telomerase. Journal of Biotechnology, 176, 50-57. http://dx.doi.org/10.1016/j.jbiotec.2014.02.017

[15] Lawley, T.D., Bouley, D.M., Hoy, Y.E., Gerke, C., Relman, D.A. and Monack, D.M. (2008) Host Transmission of Salmonella enterica serovar Typhimurium Is Controlled by Virulence Factors and Indigenous Intestinal Microbiota. Infection and Immunity, 76, 403-416. http://dx.doi.org/10.1128/IAI.01189-07

[16] Steele-Mortimer, O., Brumell, J.H., Knodler, L.A., Méresse, S., Lopez, A. and Finlay, B.B. (2002) The Invasion-associated Type III Secretion System of Salmonella enterica serovar Typhimurium Is Necessary for Intracellular Proliferation and Vacuole Biogenesis in Epithelial Cells. Cellular Microbiology, 4, 43-54. http://dx.doi.org/10.1046/j.1462-5822.2002.00170.x

[17] Jantsch, J., Cheminay, C., Chakravortty, D., Lindig, T., Hein, J. and Hensel, M. (2003) Intracellular Activities of Salmonella enterica in Murine Dendritic Cells. Cellular Microbiology, 5, 933-945. http://dx.doi.org/10.1046/j.1462-5822.2003.00334.x 
[18] Huppertz, H. and Heesemann, J. (1997) Invasion and Persistence of Salmonella in Human Fibroblasts Positive or Negative for Endogenous HLA B27. Annals of the Rheumatic Diseases, 56, 671-676. http://dx.doi.org/10.1136/ard.56.11.671

[19] Oswald, E., Nougayrède, J.P., Taieb, F. and Sugai, M. (2005) Bacterial Toxins That Modulate Host Cell-Cycle Progression. Current Opinion in Microbiology, 8, 83-91.

http://dx.doi.org/10.1016/j.mib.2004.12.011

[20] Schafer, K.A. (1998) The Cell Cycle: A Review. Veterinary Pathology, 35, 461-478. http://dx.doi.org/10.1177/030098589803500601

[21] Pietenpol, J.A. and Stewart, Z.A. (2002) Cell Cycle Checkpoint Signaling: Cell Cycle Arrest versus Apoptosis. Toxicology, 181-182, 475-481. http://dx.doi.org/10.1016/S0300-483X(02)00460-2

[22] Walworth, N.C. (2000) Cell-Cycle Checkpoint Kinases: Checking in on the Cell Cycle. Current Opinion in Cell Biology, 12, 697-704. http://dx.doi.org/10.1016/S0955-0674(00)00154-X

[23] Jagadish, B.H. and Saxena, M.K. (2008) Salmonella Typhimurium Invasion Induces Apoptosis in Chicken Embryo Fibroblast. Current Science, 95, 512-514.

[24] Edelblum, K.L., Yan, F., Yamaoka, T. and Polk, D.B. (2006) Regulation of Apoptosis during Homeostasis and Disease in the Intestinal Epithelium. Inflammatory Bowel Disease, 12, 413-424. http://dx.doi.org/10.1097/01.MIB.0000217334.30689.3e

Submit or recommend next manuscript to SCIRP and we will provide best service for you:

Accepting pre-submission inquiries through Email, Facebook, LinkedIn, Twitter, etc. A wide selection of journals (inclusive of 9 subjects, more than 200 journals)

Providing 24-hour high-quality service

User-friendly online submission system

Fair and swift peer-review system

Efficient typesetting and proofreading procedure

Display of the result of downloads and visits, as well as the number of cited articles

Maximum dissemination of your research work

Submit your manuscript at: http://papersubmission.scirp.org/

Or contact aim@scirp.org 